\title{
A IMPORTÂNCIA DA FILOSOFIA DA EDUCAÇÃO
}

\section{ARTIGO DE REVISÃO}

PEREIRA, Lucélia de Oliveira ${ }^{1}$

SILVA, Cinthia Angélica da ${ }^{2}$

PETZOLD, Poliane da Silva ${ }^{3}$

RAVACHE, Rosana Lia ${ }^{4}$

${ }^{1}$ Mestranda do Curso de Ciências da Educação pela Instituição de ensino superior UNIGRAM/Instituto Vanguarda Curso De Mestrado, pós-graduada em Ciências Biológicas e Meio Ambiente pelo Instituto Matogrossense de pós-graduação - IMP e Graduada em Ciências Biológicas pela Universidade de Mato Grosso-Unic.

2 Mestranda do Curso de Ciências da Educação pela Instituição de ensino superior UNIGRAM/Instituto Vanguarda Curso De Mestrado, pós- graduada em Literatura Matogrossense pela Universidade do Estado de Mato Grosso - Unemat e Graduada em Letras e pós- graduada em Literatura Matogrossense pela Universidade do Estado de Mato Grosso - Unemat.

${ }^{3}$ Mestranda do Curso de Ciências da Educação pela Instituição de ensino superior UNIGRAM/Instituto Vanguarda Curso De Mestrado, pós-graduada em Educação ambiental pelo Instituto Cotemar e Graduada em Ciências Biológicas pela Universidade de Mato Grosso-Unic.

4 Doutora em Geografia Humana, mestre em Geografia Humana na área de concentração Ambiente e Desenvolvimento Regional, especialista em Terceiro Setor e Políticas Públicas pela Universidade Cândido Mendes, Graduada em Comunicação Social com ênfase em Relações Públicas, no Centro de Estudos Superiores e Pesquisa, Rio de Janeiro provisionado pelo Ministério do Trabalho, Técnica em Serviço Social formada pela Escola Profissional da República Federal da Alemanha. 
PEREIRA, Lucélia de Oliveira. Et al. A importância da filosofia da educação. Revista Científica Multidisciplinar Núcleo do Conhecimento. Ano 05, Ed. 01, Vol. 10, pp. 05-12. Janeiro de 2020. ISSN: 2448-0959, Link de acesso: https://www.nucleodoconhecimento.com.br/educacao/filosofia-da-educacao

\section{RESUMO}

O presente artigo suscita analisar a importância da filosofia da educação, baseandose em fundamentos instrutivos, que trazem consigo assuntos envoltórios, portadores de relações intrínsecas entre si. Nesse viés, contextualizaremos questões em destaque na atualidade, referentes as divergências fundamentadas na carência de uma análise filosófica aprofundada sobre o sistema educativo. O tema possui uma relação mútua com o contexto histórico e temporal inserido socialmente, pois envolve inúmeras discussões, se for considerada a performance atual do ensino brasileiro. $\mathrm{O}$ sistema educativo, muitas vezes, atua de modo a beneficiar a classe dominante, operando como forma de alienar sua "matéria" não se estabelecendo de forma homogênea em todos os parâmetros sociais do país, porque a falta de embasamento curricular e material acabam dificultando o aprendizado daqueles "menos favorecidos". Assim, como agente e produto da sociedade, visto que, aqueles que nela se formarão, irão compor a estrutura da sociedade na qual vivem; o exposto, portanto, envolve problemáticas distintas, que discutem a relevância da filosofia de educação como forma de se minimizar as disparidades que reverberam no meio social.

Palavras-chave: Filosofia, educação, sistema educativo.

\section{INTRODUÇÃO}

O Sistema educativo brasileiro tem convivido com divergências relacionadas ao produto resultante no âmbito político, social e econômico, decorrentes da ausência de análise filosófica e correção das falhas atuais, a partir de uma perspectiva ética. As mudanças do mundo contemporâneo nos âmbitos políticos, sociais ou econômicos, tem provocado uma análise de sua função nos meios sociais e, paralelamente, têm requisitado um novo modelo de trabalhador, capaz de se adaptar as constantes 
mudanças do mercado capitalista, pensando e instruindo-se constantemente. A escola deve tomar por base novos questionamentos e exames no que se refere a "saber científico único", visando a formação de cidadãos preparados, tanto no ensino privado quanto no público, ressaltando-se a importância do ensino público que o é assegurado pela Constituição de 1988.

Esta pesquisa objetiva gerar conhecimentos novos e úteis para a ciência, além de pretender ampliar o que sabemos sobre a importância da filosofia da educação. Para este estudo foi feita uma pesquisa explicativa definida, como um meio para identificar fatores que determinem ou contribuam para a ocorrência de determinados fenômenos e assim obter maior conhecimento sobre um assunto a ser explanado.

De acordo com Gil (1999), o pesquisador deve utilizar processos científicos para a solução de problemas. Para ele, a pesquisa é o processo formal e sistemático de desenvolvimento do método científico, com o qual a concepção de que pesquisar significa, de forma bem simples, procurar respostas para indagações propostas. $O$ objetivo fundamental da pesquisa é descobrir respostas para problemas mediante o emprego de procedimentos científicos e filosóficos. Atualmente, a filosofia é entendida como busca para explicações e soluções, através da revisão e reavaliação dos resultados, pretende aproximar-se cada vez mais da verdade, através de métodos que venham a proporcionar controle para chegar com êxito aos resultados obtidos (CERVO \& BERVIAN, 1983).

A técnica a ser utilizada na pesquisa será a entrevista semi-estruturada, que, de acordo com GIL (1994, p. 113), “... é uma das técnicas de coleta de dados mais utilizada (...) por pesquisadores que [tratam de problemas humanos], (...) não apenas para coleta de dados, mas também com objetivos voltados para diagnóstico e orientação...." Foi considerada semi-estruturada por conter questões abertas que ainda possibilitaram outras perguntas a partir das respostas obtidas.

Será demonstrado ainda que a filosofia é de extrema importância no processo de ensino-aprendizagem, pois desenvolve critérios que vão além da capacidade de pensar e agir e como ela está inserida no contexto da sociedade. 


\section{NOÇÕES PRELIMINARES}

A filosofia é uma ciência que se constitui no estudo de problemáticas primordiais referentes à existência humana, tratando da causa, dos efeitos e das propriedades dos seres. Etimologicamente, a palavra filosofia advém da unidade de duas sentenças gregas: philos (amor) e sophia (sabedoria). Nesse viés, se traduz filosofia como o amor ao conhecimento. Ademais, além de ser uma disciplina, a filosofia é inerente ao homem, não apenas como sabedoria, mas também como sentença natural do ser.

Assim como na ciência ou no direito, existe uma disciplina que trata de análises relacionadas a questões intrínsecas da educação denominada filosofia da educação. $\mathrm{Na}$ esfera da filosofia racional, o âmbito da educação é exposto como uma disciplina cuja finalidade é o esclarecimento das teorias pedagógicas e dos conhecimentos educacionais. Nesse contexto, o campo abordado pela filosofia da educação é formado pelos saberes e instrumentos essenciais ao esclarecimento designado pelas características daqueles conhecimentos.

De maneira sucinta, a filosofia da educação possui como objetivo primordial esclarecer o conhecimento educacional, priorizando as teorias pedagógicas, através de análises dialéticas, lógicas e retóricas. Essas, no caso da lógica, possuem como base ferramentas constituídas para realizar verificações de enunciados que se relacionem com a verdade. Esses elementos argumentativos devem ser examinados com o objetivo de se obter a compreensão e o desenvolvimento de teorias referentes ao campo educacional.

Durante muito tempo, reflexões filosóficas relacionadas à educação se restringiram a formação de jovens e crianças. Em décadas recentes, tem-se analisado a educação sobre a formação de adultos, criando-se assim, termo educação permanente. 


\subsection{A EDUCAÇÃO COMO AGENTE TRANSFORMADOR E PRODUTO DE MUDANÇA NA SOCIEDADE}

A educação se estabelece como um forte agente propositor de mudanças na sociedade, sendo perceptível a relação mútua que existe entre ambas. Diante das transformações oriundas do mundo contemporâneo, onde é exigido do trabalhador um novo perfil para o trabalho, o homem deve dispor de habilidades polivalentes e flexíveis, além de ser capaz de pensar e aprender constantemente, para poder acompanhar a dinâmica do mercado. Desse modo, a educação passa a ter um papel primordial no aprimoramento dos conhecimentos e qualidades, para que o homem possa exercer a sua parte social de modo consciente e crítica. Assim, a educação deve ser articulada com o objetivo de formar cidadãos conscientes de seus direitos e deveres sociais, bem como preparados para exercer seus trabalhos de forma ética e comprometida.

A educação, quando analisada em um contexto histórico, se caracteriza de forma distinta em todos os lugares e tempo, ligando-se intrinsecamente, à concepção humana e social que emerge do processo educativo. A partir dessas afirmações, conclui-se que a educação é, por seus objetivos, origens e funções, um processo social que está relacionado ao viés econômico, político e científico de cada sociedade.

Como afirma Dermeval Saviani:

O estudo das raízes históricas da educação contemporânea nos mostra a estreita relação entre a mesma e a consciência que o homem tem de si mesmo, consciência esta que se modifica de época para época, de lugar para lugar, de acordo com um modelo ideal de homem e de sociedade. (SAVIANI, 1991, p.55)

O processo educativo, portanto, não deve ser analisado e entendido de modo a se fragmentar da concepção imposta para qualquer lugar e tempo, uma vez que deve ser entendido como uma prática social com relações históricas. É, portanto, um fenômeno social que se adapta a cada tipo de concepção, cultural, ou seja, é o processo 
educativo vigente que determina os objetivos a serem atingidos de acordo com as ideologias que dominam determinada sociedade.

A educação se desenvolve a partir de um paradigma, cuja intenção é reproduzir os aspectos políticos, econômicos e sociais de uma dada sociedade. Nessa perspectiva, tomando-se por base o progresso evolutivo do sistema capitalista em distintas épocas, fica evidenciado que o fenômeno educativo tem sido utilizado com o fim de estruturar ideologicamente o sistema, estruturando todo o meio com o fim de fornecer elementos produtivos e recursos para o desenvolvimento capital.

De acordo com Capra:

O paradigma que está agora retrocedendo dominou a nossa cultura por várias centenas de anos, durante os quais modelou nossa moderna sociedade ocidental e influenciou significativamente o restante do mundo. Esse paradigma consiste em várias ideias e valores entrincheirados, entre os quais a visão de universo como um sistema mecânico composto de blocos de construção elementares, a visão de corpo humano como uma máquina, a visão da vida em sociedade como uma luta competitiva pela existência, e a crença no progresso material ilimitado, a ser obtido pelo intermédio do crescimento econômico e tecnológico. (CAPRA, 1996, p.25).

Sendo assim a filosofia faz parte do contexto da capacidade humana de pensar e gerar um caráter crítico que visa à construção de uma sociedade construtiva e que busca liberdade de expressão, construindo seres pensantes a partir de uma problemática que analise fatores, sem nem um tipo de preconceito, como um fator enraizado em nossa sociedade.

Em alguns casos foram percebidas as reais funcionalidades capitalistas bem como de que forma a educação teria sido utilizada para o seu progresso, em distintos casos que promoveram reações por parte dos indivíduos. A instabilidade social prediz um 
hodierno saber, estruturado por meio de um novo parecer científico que expõe uma racionalidade mais diversificada.

A educação é um agente que possui grande impacto sobre a sociedade; é uma opinião consensual, que ela promove significativas mudanças. Com isso, é possível afirmar, que a educação deve libertar-se de paradigmas impostos por grupos sociais vigentes que atuam com o único intuito de fortalecer e expandir seu capital, mesmo que para isso utilize ferramentas educativas alienantes para tomar os indivíduos e torná-los dependentes.

De maneira análoga, a educação e a sociedade são interdependentes no que se refere ao progresso; uma avançará apenas com o avanço da outra. Defensores da revolução educacional afirmam que com um maior acesso ao conhecimento e disposição de recursos para isso, a população teria mais elementos para tomar melhores decisões e reconhecer de modo crítico a realidade que nos cerca.

\subsection{A IMPORTÂNCIA DE UMA ANÁLISE FILOSÓFICA DO PAPEL ÉTICO DA EDUCAÇÃO NA SOCIEDADE}

No mundo contemporâneo tornou-se algo comum falar sobre ética. Associada ao ramo da filosofia que investiga os valores morais que instrui o comportamento humano em sociedade. Ao se mencionar o assunto, logo surgem na mente as questões relacionadas ao convívio com o outro que é diferente, porém um ser humano como todos. A ética não lida apenas com o interesse de forma individual; coletiva, lida de forma, focando na maneira de tratar as predileções de um grupo.

No âmbito educativo, quando se fala em ética, logo se prevê a atuação dos professores em relação aos seus docentes. A ética estabelece valores gerais, atuando em os princípios que conduzem a ação e designam regras para o bem comum.

De acordo com Morin

Como dizia magnificamente Durkheim o objetivo da educação não é o de transmitir conhecimentos sempre mais numerosos ao aluno, mas o 
"de criar nele um estado interior e profundo uma espécie de polaridade de espírito que oriente em um sentido definido, não durante a infância, mas por toda via. (MORIN, 2004.p.47).

Assim, a educação gira em torno dos educandos. Embora a escola não seja o único agente responsável pela formação moral e ética dos cidadãos, ela possui uma grande parte da responsabilidade. Diante do cenário de instabilidade política, social e econômica que o Brasil enfrenta na atualidade é frequente nos depararmos com discursos moralistas "clichês", sugerindo qual deveria ser o comportamento adotado pelos políticos, atribuindo-Ihes diversas regras comportamentais éticas. Em contrapartida, existe uma carência de reflexões que abordem as raízes históricas desses problemas, e auxiliem nas possíveis soluções ou que, pelo menos, minimizem esses "desvios", presentes nos alicerces da cultura política do Brasil.

A análise filosófica do âmbito educativo, exerce um importante papel na fundamentação das condutas éticas. Nesse contexto, é essencial perceber que "fragilidades" de atitudes morais não se limitam a ações daqueles que ocupam cargos públicos. É comum nos depararmos com valores permissivos que atribuídos à definição de "jeitinho brasileiro", que encobre atitudes antiéticas transformando-as em virtudes, relacionadas quando na realidade, estão a comportamentos que contradizem as regras sociais, no intuito de estabelecer privilégios de uns. $O$ fato dessas condutas chegarem a serem consideradas como habilidades de pessoas espertas e inteligentes, revela a fragilidade da educação brasileira, que tem formado indivíduos incapazes de pensar no próximo como um igual. Sob esta ótica, grande parcela das divergências éticas do âmbito da política governamental, pode possuir soluções naquilo que constitui a base política e cultural da sociedade: a educação.

Este fenômeno de instabilidade social que presenciamos na atualidade, reverbera por meio da violência, ódio, preconceito e corrupção, um alerta para que seja feita, urgentemente uma análise filosófica profunda do papel ético da educação na sociedade. 


\subsection{A NECESSIDADE DE UMA ANÁLISE FILOSÓFICA DA EDUCAÇÃO PARA A CONSTRUÇÃO DE UM PROJETO EDUCACIONAL AMPLO}

Em detrimento dos atuais desafios e mudanças da sociedade, a formação é tida como necessária de cidadãos capazes de compreender o meio em que vivem, para que reconheçam de maneira crítica, as divergências. No entanto, a educação brasileira possui diversas fragilidades referentes a educação inclusiva, na qual, grupos quantitativamente minoritários possuem privilégios sobre o demais de maneira homogênea e ampla impedindo que a educação seja estabelecida.

Um fundamento que retrata bem a condição degradante do ensino brasileiro é a situação do ensino público em esfera nacional. O Brasil possui atualmente cerca de 20 milhões de analfabetos. Paralelamente, alunos que cursam em Instituições públicas, frequentemente apresentam impedimentos de aprendizagem ocasionados pela degradante condição curricular e estrutural do ensino público.

Lê-se, pois, que é paradoxal que um Estado Democrático, cuja Constituição, propõe com clareza, a obrigação do ensino educativo de qualidade, procrastine, para certa parcela, um direito previsto constitucionalmente. Assim, é de extrema importância que a filosofia da educação repense os âmbitos inclusivos desta camada da sociedade.

\section{CONSIDERAÇÕES FINAIS}

Conclui-se, portanto, que a filosofia da educação é uma disciplina de extrema importância na atualidade e sua aplicação é de indubitável eficácia como ferramenta para tratar das questões do ser humano, assim como dos seus efeitos e causas.

Constatamos, que as questões relacionadas à educação não podem ser articuladas sem a presença da filosofia. Desde os primórdios da formação da unidade social, ambas vem sendo discutidas e vivenciadas como assuntos coadunados e incluídos na perspectiva de ensino, com diversas ideias orientadas pelos primeiros filósofos e perpetuadas com o intuito de desenvolver o senso crítico do aluno e torná-lo capaz exercer o senso argumentativo e desenvolver o autoconhecimento e reflexão. É 
necessário entender os filósofos e suas proposições, para que um novo entendimento da realidade seja abordado. Esse entendimento do real é primordial para o meio, pois na sociedade existe uma assídua busca por aqueles capazes de fazer a diferença. Assim podemos conceituar a filosofia da educação como sendo um conjunto de ideias que define como é a educação e o quanto ela é importante não só no contexto escolar, mas também para a vida social, tornando-nos capazes de desenvolver habilidades de conhecimento, pensamento e atitudes diante dos fatos que nos rodeiam e permanecem raizados na sociedade. Sendo assim, a filosofia busca formar cidadãos mais críticos e que saibam analisar os fatos com capacidade de entendimento da realidade e que desempenhem seus papéis como agentes da sociedade, propondo soluções para os desafios encontrados em um mundo globalizado e saturado de informações.

\section{REFERÊNCIAS}

BRASIL. Constituição (1988). Constituição da República Federativa do Brasil. Brasília, DF, Senado, 1998.

FERREIRA, Naura Syria Carapeto; AGUIAR, Márcia Ângela da Silva. (Orgs). Gestão da Educação: Impasses, perspectivas e compromissos. 2 ed. São Paulo: Cortez, 2001

SAVIANI, D. Educação: do senso comum à consciência filosófica. 10 ed. São Paulo: Cortez: Autores Associados, 1991.

FRIGOTTO, G. Educação e a crise do capitalismo real. 3 ed. São Paulo: Cortez,1999.

SANTOS, Joelma Coelho; TEIXEIRA, Ranessa Lira; SOUZA, Nory Lana. Filosofia, Ética e Sociedade. Disponível em: < https://www.sabedoriapolitica.com.br/products/filosofia-etica-e-sociedade/>. Acesso em 09 jun. 2018. 
NOVAKOSKI, Hermes José. A IMPORTÂNCIA DA FILOSOFIA NA EDUCAÇÃO. Disponível em: < https://www.recantodasletras.com.br/artigos-deeducacao/2434695>. Acesso em 09 jun. 2018.

SANTOS, Joelma Coelho; TEIXEIRA, Ranessa Lira; SOUZA, Nory Lana. Filosofia, Ética e Sociedade. Disponível em: < https://www.sabedoriapolitica.com.br/products/filosofia-etica-e-sociedade/>. Acesso em 09 jun. 2018.

WITTMANN, Lauro Carlos; KLIPLEL, Sandra Regina. A prática da gestão democrática no ambiente escolar. Curitiba: IBPEX, 2010. (Série Processos Educacionais).

Enviado: Dezembro, 2019.

Aprovado: Janeiro, 2020. 